There is no national mental health professional association, though there are service users' and carers' groups supporting people with epilepsy and intellectual disabilities. There is some professional interaction with other Francophone African countries (e.g. through the West African Health Organisation, WAHO) and French universities have some academic collaboration with Nigerien institutions. The division between Francophone and Anglophone traditions is a significant barrier to accessing information, given that the majority of journals and online resources are in English.

\section{Research}

There has been little systematic epidemiological data collected, but some ethnographic research was carried out in the 1970s and 1980s (Osouf, 1980). A national survey is currently being undertaken by the Ministry of Health as part of the process of policy development and planning.

\section{National policy and plans}

A national mental health policy was formulated in 1993, and a national mental health plan was developed with help from the WHO in 1995, revised in 2000 and 2004 (Ministère de la Santé, 2000). Unfortunately, practical implementation of the plan did not progress beyond some training activities. There has been little long-term impact of the principles of decentralisation of services that formed the core of these policies and plan.

Even with strong advocacy, it is unlikely that there will be adequate funds in the national budget for implementation of a programme unless it is supported by an outside agency. This is in common with other sectors, but the fact that mental health is not specifically mentioned as a Millennium Development Goal makes finding resources more challenging. The integration of mental health as a cross-cutting issue within other areas is one option (Prince et al, 2007), but working towards a specific mental health policy is also important (Jenkins, 2003).

A good relationship is emerging between the government, the WHO country office, and the non-governmental sector (a major healthcare provider in Niger), who are working together to revise the national policy and plan. The ultimate aim of this process is more accessible care, in line with recent international initiatives to scale up services in low- and middle-income countries and to ensure that human rights issues are taken into account (Chisholm et al, 2007). The national plan also incorporates participation of service users and other stakeholders in order to ensure that the process has a meaningful impact on their quality of life.

A pilot programme of service delivery following the latest evidence-based guidelines (Thornicroft \& Tansella, 2004) is in development; it integrates a modified community-based rehabilitation model (Chatterjee et al, 2003) into primary care. This takes into account the importance of the nongovernmental sector in a country like Niger. If successful, the pilot will be replicated nationwide.

\section{References}

Chatterjee, S., Patel, V., Chatterjee, A., et al (2003) Evaluation of a community-based rehabilitation model for chronic schizophrenia in rural India. British Journal of Psychiatry, 182, 57-62.

Chisholm, D., Flisher, A. J., Lund, C., et al (2007) Scale up services for mental disorders: a call for action. Lancet, 370, 1241-1252.

Cohen, A. (2001) The Effectiveness of Mental Health Services in Primary Care: The View from the Developing World. WHO

Eaton, J. (2008) Ensuring access to psychotropic medication in subSaharan Africa. African Journal of Psychiatry, 11, 179-181.

Jenkins, R. (2003) Supporting governments to adopt mental health policies. World Psychiatry, 2, 14-19.

Ministère de la Santé (2000) Programme National de Sante Mentale [National Programme of Mental Health.] Ministère de la Santé

Osouf, P. (1980) Regard sur I'assistance psychiatrique au Niger [On psychiatric assistance in Niger.] Psychopathologie Africaine (Dakar), 16, 249-279.

Prince, M., Patel, V., Saxena, S., et al (2007) No health without mental health. Lancet, 370, 859-877.

Thornicroft, G. \& Tansella, M. (2004) Components of a modern mental health service: a pragmatic balance of community and hospital care. Overview of systematic evidence. British Journal of Psychiatry, 185 283-290.

UNICEF (2008) Country statistics, at http://www.unicef.org/infobycountry/ niger_statistics.html (accessed 15 December 2008).

World Bank (2007) World development indicators database, at http:// www.worldbank.org/datastatistics (accessed 15 December 2008).

WHO (2005) Atlas. Mental Health Resources in the World. World Health Organization.

\title{
Psychiatry in Switzerland
}

\section{Dan Georgescu}

Department of Old Age Psychiatry, Königsfelden Hospital, Brugg, Switzerland, email dan.georgescu@pdag.ch

\footnotetext{
witzerland - officially the Swiss Confederation - is a federal republic situated in central Europe. It covers an area of $41287 \mathrm{~km}^{2}$ and has a population of just over 7600000 . Switzerland consists of 26 federated states, of which 20 are called cantons and 6 are called half-cantons. German, French and Italian are Switzerland's major and official languages.
}

Switzerland has the second highest per capita level of healthcare spending as a proportion of gross domestic product (11.3\%). Although there are no exact data available, based on international comparisons, one may assume that at least 10 $12 \%$ of total healthcare costs are attributable to mental health problems. A characteristic of Swiss society and therefore of Swiss psychiatry is the federal and liberal tradition. Although 
there is hardly any central state coordination of mental health policy, there is to some degree a homogeneous level of care services throughout the whole country. The cohabitation of the public and private sectors reflects the liberal tradition. Swiss modern psychiatry goes back to the second half of the 19th century, when the first psychiatric hospitals and chairs and a professional association of psychiatrists were founded.

\section{Mental health policy and legislation}

On a political level, there is no national mental health policy, common strategy or binding principles to ensure the uniform national delivery of psychiatric care. The national strategy for mental health, developed in 2004 by the Federal Department for Health, is actually only a guide to help the cantons and the federal government design concrete projects.

Even with respect to involuntary admission, there is no uniform legal framework at a national level, but only basic federal legislation (article 397 of the Code of Civil Law), with corresponding supplementary laws on preventive custody at the cantonal level. With respect to compulsory treatment there is only a guideline entitled Compulsory Measures in Medicine of the Swiss Academy for Medical Sciences. Further legal documents relevant to psychiatry are, at the national level, those regarding the right of self-determination, bodily injury and a duty to take care, as well as, at the cantonal level, health laws and patient decrees. There are several decisions of the Federal Tribunal determining the duty to obtain informed consent.

An important milestone of Swiss health law, the federal health law of 2006 regarding the academic medical professions, regulates the training, specialty-related and personal licensing conditions and the professional duties of physicians. This law strongly influences not only the universities but also private practice, as well as the law-makers at canton level.

\section{Mental health services}

\section{Funding}

In Switzerland, the cantons are in charge of the organisation of mental health services. The cantonal healthcare concepts differ to a certain extent as far as the services offered and the health delivery structures are concerned. However, in recent years a certain degree of convergence has occurred, although the federal structure has favoured a fragmentation of the funding agencies and the healthcare providers.

Services provided by the psychiatric hospitals are reimbursed mainly by health insurance companies - mandatory insurance being imposed since 1996 by the Law on Sickness Insurance for all Swiss residents - and by the cantons. Private funding, additional private insurance and the municipalities contribute to the funding to a much more moderate extent. Out-patient treatment is covered mainly by health insurance, followed by self-payment for such treatment.

Consultations in private practice are reimbursed also for those patients who have only basic (mandatory) health insurance, provided that the psychiatrist is recognised by the cantonal authority. Those with additional, private health insurance have a choice of hospital, even if this is situated in another canton or if it is a private one.
Besides psychiatrists there are also many psychologists practising in the private sector, their bills being reimbursed only for patients with additional insurance.

Traditionally, the Swiss greatly value the ability to make their own choice in matters related to healthcare, but in the last decade political pressure has come from both the state and the insurance companies to limit the number both of doctors in private practice and of reimbursed sessions of psychotherapy, as well as to introduce a system of managed care, including gatekeepers. This pressure, aimed at reducing healthcare costs, has stirred up some controversies and confrontations in Switzerland.

\section{Service delivery}

At present there are 1.06 psychiatric beds (forensic and addiction psychiatry beds not included) per 1000 inhabitants; there has been a continuous reduction in recent years in the number of beds in hospitals, in favour of community-based settings. Under the slogan 'ambulant before hospital', out-patient care and day hospital care have been extended to assume a major role in prevention, crisis intervention and rehabilitation. Despite the expansion of community-based services in recent years, there are differences in the availability of psychiatric services as well as private practices - between urban and rural areas.

Mental health services are delivered by the state as well as by the private sector. The cantonal governments are responsible for the organisation of psychiatric care in the state sector. The state sector includes a wide range of well equipped services with a high degree of specialisation. In addition to general adult psychiatry and child and adolescent psychiatry, the psychiatric institutions also have substance dependence, old age, psychosomatic medicine and liaison psychiatry services, as well as forensic psychiatry services.

The private sector consists of eight private psychiatric institutions and psychiatrists working in private practice. The private institutions offer in-patient as well as outpatient facilities for a range of mental disorders, with the exception of severe psychotic illness and hostile, agitated or self-harming behaviours.

It should be emphasised that mental healthcare in Switzerland involves cooperation between psychiatric services (both state and private) and adjacent sectors, such as public health, disability services, social services, youth welfare services and senior services, as well as justice and police.

\section{Workforce issues and professional organisations}

Relative to its population, Switzerland has the highest number of psychiatrists in the world: 30 per 100000 inhabitants, according to the World Health Organization (WHO). At present, Switzerland has, according to the Federal Department of Health, 2603 adult psychiatry specialists, of whom 2016 are in private practice, the rest being employed in public institutions. For child and adolescent psychiatry the numbers are 1257 (overall) and 439 (in private practice). However, the overall number of psychiatrists is actually significantly higher, given that many psychiatrists with foreign diplomas, working mainly in state hospitals, are not included in these statistics. Thirty-nine per cent of adult psychiatrists and $47 \%$ of child and adolescent psychiatrists are female. 
The Swiss Society of Psychiatry and Psychotherapy (SSPP) - which includes among others the cantonal psychiatric societies and the affiliated subspecialty organisations - has 1884 members; the Swiss Society of Child and Adolescent Psychiatry and Psychotherapy (SSCAPP) has 592 members.

In 2002, the SSPP and SSCAPP co-founded an umbrella organisation, the Foederatio Medicorum Psychiatricorum et Psychotherapeuticorum (FMPP), to promote the common interests of the two psychiatric associations. The Bulletin Psy \& Psy is the common organ of the SSPP and the SSCAPP, informing its readers about issues of professional politics. The joint website is www.psychiatrie.ch.

\section{Training}

\section{Undergraduate training}

Undergraduate medical education in Switzerland lasts 6 years. There are six medical schools, in Basel, Berne, Geneva, Lausanne, Zurich and Fribourg, though the last offers only the pre-clinical, basic curriculum. All medical schools are subsidised by their home cantons. At the undergraduate level there are three disciplines concerned with mental health: psychosocial medicine, adult psychiatry and child and adolescent psychiatry.

\section{Postgraduate training in psychiatry}

Responsibility for the education of medical specialists lies with the Swiss Medical Association (Foederatio Medicorum Helveticorum, FMH) and the medical professional associations, on behalf of the Federal Department of Home Affairs. The professional associations develop the training programmes, which are afterwards examined and put into force by the FMH, whereas the diplomas are issued by the Federal Department. Devising the psychiatric training curriculum and its periodic review, organising and administering the specialty board examinations as well as visits to the training centres are the responsibility of the Standing Committee on Psychiatric Training and Education of the SSPP. The Committee includes representatives of the universities, of the training directors, of psychiatrists in private practice, of trainees, and so on.

The recently revised competence-based training programme is due to become effective in 2009. It stipulates a 6-year residency, of which 1 year is to be spent in a somatic specialty and 5 in psychiatry. Both in-patient and out-patient settings need to be part of the residency experience, and a rotation between different institutions is required.

Training in psychiatry and psychotherapy is decentralised and not a matter only for university centres. Around 150 psychiatric institutions of varying size are recognised by the $\mathrm{FMH}$ as places of residency, each with an a priori specified period of recognised training, in a hospital or ambulant setting, and psychiatric subspecialty.

Theoretical psychiatric education is offered within the framework of the eight regional networks for postgraduate education. Together with psychiatric training in the narrow sense, trainees are taught the basics of health economics, the legal foundation and ethical aspects of psychiatric practice. Training in psychotherapy, which accounts for a considerable part of the postgraduate programme, is provided by SSPP-recognised private institutes of psychotherapy in German-speaking Switzerland, as well as by the universities in the French-speaking part. The current residency programme stipulates 3 years of training in one of the recognised models (psychoanalytic, cognitive-behavioural or systemic). Traditionally, efforts have been made to ensure the Swiss curricula have a well balanced biological and psychosocial content.

\section{Psychiatric subspecialties}

Child and adolescent psychiatry developed at the beginning of the 20th century out of adult psychiatry and paediatrics. In Switzerland, the development started early, in comparison with other European countries, with the establishment of care structures specific to this age group. Child and adolescent psychiatry became a separate psychiatric discipline in 1953. It has its own chairs in all medical schools, 30 postgraduate training centres as well as more than 17 cantonal services with out-patient as well as in-patient or day hospital structures. Although Switzerland boasts a higher incidence of child and adolescent psychiatrists than its neighbours, the supply of such services is insufficient, in particular outside the densely populated cities.

The first subspecialty of adult psychiatry to be officially recognised by the Medical Chamber was old age psychiatry (2005), followed by consultation-liaison psychiatry (2008). For old age psychiatry, several university chairs have already been established; there are 37 training centres and about 100 certified old age psychiatrists. At present, there are ongoing efforts to establish two further psychiatric subspecialties (forensic psychiatry and addiction psychiatry).

\section{Research and scientific journals}

Swiss research in psychiatry has always been valued nationally and internationally. Research is done at all the universities, mostly of a clinical nature or on basic science. Currently, there is a tendency to form collaborative research groups connecting several neurosciences.

The only Swiss psychiatric journal still published is Swiss Archives of Neurology and Psychiatry (founded 1917, eight issues a year, published in German, French and English). Swiss authors are frequently present on the editorial boards of widely distributed scientific journals in English, German, French and Italian.

\section{Sources}

Bundesamt für Gesundheit (BAG) (2009) Psychische Gesundheit [Mental health], at http://www.bag.admin.ch/themen/medizin/00683/01916/ index.html?lang=de (accessed May 2009).

Foederatio Medicorum Helveticorum (FMH) (2001) Facharzt für Psychiatrie und Psychotherapie. Weiterbildungsprogramm [Psychiatry and Psychotherapy: Programme of Specialist Education.], at http://www. $\mathrm{fmh} . \mathrm{ch} / \mathrm{de} / \mathrm{data} / \mathrm{pdf} /$ psychiatrie_version_internet_d.pdf (accessed May 2009).

Joint Conference of Swiss Medical Faculties (SMIFK) (2002) Swiss Catalogue of Learning Objectives for Undergraduate Medical Training, at http://sclo.smifk.ch (accessed May 2009).

Schweizerische Gesundheitsdirektorenkonferenz (GDK) (2008) Leitfaden zur Psychiatrieplanung [Guideline for psychiatry planning], at http:// www.gdk-cds.ch/fileadmin/pdf/Themen/Gesundheitsversorgung/ Versorgungsplanung/Psychiatrieplanung/GDK-Psychiatrieplanung15d__def_.pdf (accessed May 2009). 